\title{
Conhecimento cronobiológico e hábitos de sono de acadêmicos da Universidade Paranaense
}

\author{
Chronobiologic acquaintance and sleep habits of academics of the Universidade Paranaense \\ Liziane Seibt ${ }^{1}$, Vanessa Morais Lima ${ }^{2}$, Kleber Fernando Pereira ${ }^{3}$, Fabio José \\ Bianchi ${ }^{4}$, Larissa Renata de Oliveira Bianchi ${ }^{5}$
}

\begin{abstract}
RESUMO
Introdução. A cronobiologia estuda os ritmos biológicos de animais, plantas e seres humanos, sabendo-se que em um período determinado as funções fisiológicas e comportamentais do organismo se alteram, ocorrendo uma variação para respostas e estímulos decorrentes do ambiente externo. Objetivo. Identificar o perfil cronobiológico e sua relação com hábitos de sono de acadêmicos da $4^{\text {a }}$ série, noturno e matutino do Curso de Ciências Biológicas da Universidade Paranaense. Método. A metodologia aplicada faz uso de um padrão de questionário cronobiológico, composto por 9 questões objetivas, além de 8 questões estruturadas com o objetivo de identificar hábitos de sono. Resultados. Dos 46 acadêmicos entrevistados do matutino, verificou-se que $28,27 \%$ são moderadamente matutino, estando em período compatível com seu cronotipo, à maioria $43,48 \%$ possuem cronotipo intermediário, possuindo maior adaptação a qualquer horário em que venha realizar atividades. Dos 32 acadêmicos entrevistados do noturno, constatou-se que $28,13 \%$ são moderadamente matutino, em desacordo com seu cronotipo, 50\% intermediário podendo se adaptar a qualquer horário que esteja realizando atividades, e 15,63\% moderadamente vespertino, de acordo com seus ritmos biológicos. Conclusão. Quando os acadêmicos passarem a conhecer seu cronotipo, poderão se adaptar melhor ao seu horário de estudo possibilitando uma maior aprendizagem e assimilação dos conteúdos.

Unitermos. Cronobiologia, Sono, Acadêmicos

Citação. Seibt L, Lima VM, Pereira KF, Bianchi FJ, Bianchi LRO. Conhecimento cronobiológico e hábitos de sono de acadêmicos da Universidade Paranaense.
\end{abstract}

Trabalho realizado na Universidade Paranaense, Cascavel-PR, Brasil.

1. Bióloga pela Universidade Paranaense, Cascavel-PR, Brasil.

2. Acadêmica de Ciências Biológicas na Universidade Federal de Goiás, Jataí-GO, Brasil.

3. Educador Físico, Mestre em Anatomia Humana pela USP, docente do curso de Ciências Biológicas da Universidade Federal de Goiás, Jataí-GO, Brasil.

4. Dentista, Doutor em Biologia Buco-dental na UNICAMP, docente do curso de odontologia da Universidade Paranaense, Cascavel-PR, Brasil.

5. Bióloga, Mestre em Anatomia Humana pela USP, docente do curso de Ciências Biológicas da Universidade Paranaense, Cascavel-PR, Brasil.

\section{SUMMARY}

Introduction. Chronobiology studies the biological rhythm of animals, plants and human beings, knowing that in a particular period, the behavioral and physiological functions of the body are changed, occurring variation for responses and stimuli due to external environment. Objective. Identify the chronobiological profile of who attends the fourth year of the Biological Science at Universidade Paranaense. Method. The methodology applied made use of a standard chronobilogical questionnaire, composed by 9 objective questions, and 8 structured questions aiming to identify sleeping habits. Results. From 46 students who were interviewed in the morning shift 28.27 moderately morning, period consistent with its chronotype, and that the most of them, $43.48 \%$ have intermediate chronotype, having a greater adaptation to any time that will carry out activities. From the 32 students interviewed in the night shift, $28.13 \%$ moderately morning, being at odds with its chronotype, $50 \%$ intermediate, able to adapt to any schedule that is performing its activities and $15.63 \%$ moderately afternoon meeting in accordance with their biological rhythms. Conclusion. When the students get to know their chronotype, they can adapt better to their studying schedule enabling a better learning and assimilation of the subjects.

Keywords. Chronobiology, Chronotype, Sleep, Academics. Citation. Seibt L, Lima VM, Pereira KF, Bianchi FJ, Bianchi LRO. Chronobiologic acquaintance and sleep habits of academics of the Universidade Paranaense.

Endereço para Correspondência: Kleber F Pereira Universidade Federal de Goiás, Campus Jataí, Unidade Jatobá. BR 364 - KM 192, Setor Parque Industrial CEP 75800-000, Jataí-GO, Brasil. E-mail:kpereira@usp.br

Recebido em: 12/03/2009 Revisado em: 13/03/2009 a 31/08/2009

Aceito em: 01/09/2009

Conflito de interesses: não 


\section{INTRODUÇÃO}

A cronobiologia estuda os ritmos biológicos dos seres vivos, uma vez que cada organismo possui seu próprio relógio biológico. Podendo ser classificado conforme o funcionamento interno do corpo, provocando alterações bioquímicas, fisiológicas e comportamentais ${ }^{1-5}$.

Os estudos cronobiológicos demonstram que praticamente todas as variáveis fisiológicas apresentam uma flutuação regular e periódica em sua intensidade ao longo das 24 horas do dia. Demonstram, também, que, além dessa variação quantitativa, os diversos sistemas fisiológicos respondem a um mesmo estímulo de forma diferente, de acordo com a hora do dia 6 .

O ser humano possui um período do dia em que se encontra mais ativo e com maior facilidade para o aprendizado e para a realização de diversas tarefas. Desta forma os indivíduos podem ser classificados em moderadamente matutino, definitivamente matutino, intermediário, moderadamente vespertino ou definitivamente vespertino conforme o funcionamento do seu ritmo biológico ${ }^{5,7-11}$.

Assim sendo, os conhecimentos cronobiológicos deveriam ser mais divulgados, não só entre professores, mas também entre os dirigentes de escolas e de órgãos gerenciadores que determinam as regras de funcionamento para as mesmas. A divulgação poderia enfatizar a importância da adequação dos horários dos docentes aos seus respectivos cronotipos. Sabemos que indivíduos bem dispostos trabalham mais satisfeitos e expressam mais facilmente sua capacidade, fato que poderia refletir positivamente na qualidade das aulas ministradas e nas atitudes do professor na sala de aula, contribuindo para a eficácia dos métodos de aprendizagem.

Ao longo das 24 horas do dia cada indivíduo se encontra em estado funcional distinto ocorrendo alternâncias entre o dia e a noite, ciclo claroescuro, não sendo possível exigir o mesmo nível de produtividade em qualquer momento do dia, para execução de qualquer tarefa e para qualquer trabalhador, por isto torna-se importante o estudo da cronobiologia $2-4,9,11-14$.

A hora do dia é importante para o aprendizado, pois muitas das dificuldades e dos problemas de adaptação ao trabalho ou a escola são decorrentes da má adequação aos ritmos biológicos, podendo trazer dificuldades para a fixação do conteúdo e falta de atenção, 10,15.

Este trabalho tem como objetivo identificar o perfil cronobiológico e hábitos de sono dos acadêmicos da 4a série matutino e noturno de ambos os sexos, do Curso de Ciências Biológicas do ano de 2006, de uma universidade privada de Cascavel $-\mathrm{PR}$.

\section{MÉTODO}

\section{Amostra}

Esta pesquisa foi realizada com acadêmicos da $4^{\text {a }}$ série, sendo 46 acadêmicos do período matutino, 14 do sexo masculino e 32 do sexo feminino, com idades variando entre 19 e 36 anos e 32 acadêmicos do período noturno, 14 do sexo masculino e 18 do sexo feminino, com idades variando entre 19 e 41 anos, do Curso de Ciências Biológicas, no ano de 2006 da Universidade Paranaense na cidade de Cascavel - Paraná. O protocolo de pesquisa foi aprovado pelo Comitê de Ética em Pesquisa envolvendo seres humanos da Universidade Paranaense (UNIPAR), em reunião realizada dia 29/06/2006, sob protocolo $07032 / 2006$.

\section{Procedimento}

Para levantamento dos dados foi aplicado um questionário durante os períodos em que os acadêmicos estudam, e que após assinarem o termo de consentimento livre e esclarecido, responderam individualmente as 9 questões objetivas relacionadas à cronobiologia, de acordo com questionário padrão proposto por Horne e Ostberg ${ }^{16} \mathrm{e}$ adaptado por Cardinalli et al. ${ }^{17}$, para identificação dos cronotipos.

Os resultados do questionário padrão foram obtidos através de contagem de pontos, utilizando a tabela de valores, para que os acadêmicos fossem classificados em moderadamente matutino, definitivamente matutino, intermediário, moderadamente vespertino ou definitivamente vespertino.

Para que fosse possível identificar os hábitos de sono dos acadêmicos entrevistados, aplicou-se ainda um questionário contendo 8 questões estruturadas, com respostas objetivas, observadas no Quadro 1. 
Quadro 1. Identificação dos hábitos de sono dos acadêmicos da $4^{\circ}$ série período matutino do Curso de Ciências Biológicas.

\begin{tabular}{|c|c|c|c|c|c|c|}
\hline $\begin{array}{l}\text { 1) Costuma } \\
\text { acordar durante } \\
\text { o período de } \\
\text { sono noturno? }\end{array}$ & () $\mathrm{Sim}$ & () Não & & & & \\
\hline $\begin{array}{l}\text { 2) Caso a resposta } \\
\text { anterior seja sim, } \\
\text { quantas vezes des- } \\
\text { perta durante o } \\
\text { sono? }\end{array}$ & $\begin{array}{l}A() 1 \\
\text { vez }\end{array}$ & $\begin{array}{l}\mathrm{B}() 2 \\
\text { vezes }\end{array}$ & $\begin{array}{l}C() 3 \\
\text { vezes }\end{array}$ & $\begin{array}{l}D(\text { () } 4 \\
\text { vezes }\end{array}$ & $\begin{array}{l}E() 5 \\
\text { vezes }\end{array}$ & \\
\hline $\begin{array}{l}\text { 3) Quando acorda } \\
\text { durante o sono e } \\
\text { volta a dormir, sen- } \\
\text { te-se descansado } \\
\text { ao acordar? }\end{array}$ & $\begin{array}{l}\text { A ( ) } \\
\text { Nada } \\
\text { can- } \\
\text { sado }\end{array}$ & $\begin{array}{l}\text { B ( ) Um } \\
\text { pouco } \\
\text { can- } \\
\text { sado }\end{array}$ & $\begin{array}{l}C() \\
\text { Muito } \\
\text { can- } \\
\text { sado }\end{array}$ & & & \\
\hline $\begin{array}{l}\text { 4) Faz uso de al- } \\
\text { guma substância } \\
\text { para poder dor- } \\
\text { mir? (Ex:. chás, me- } \\
\text { dicamentos }\end{array}$ & () $\mathrm{Sim}$ & () Não & & & & \\
\hline $\begin{array}{l}\text { 5) Tem algum dos } \\
\text { hábitos abaixo re- } \\
\text { lacionados, antes } \\
\text { de dormir? }\end{array}$ & $\begin{array}{l}\mathrm{A}(\mathrm{)} \\
\text { Comer }\end{array}$ & $\begin{array}{l}\text { B ( ) Ver } \\
\text { tele- } \\
\text { visão }\end{array}$ & $\begin{array}{l}C() \\
\text { Ouvir } \\
\text { músi- } \\
\text { ca, ou } \\
\text { deixar } \\
\text { o som } \\
\text { ligado }\end{array}$ & $\begin{array}{l}\mathrm{D}() \\
\mathrm{Fu}- \\
\text { mar }\end{array}$ & $\begin{array}{l}\text { E ( ) } \\
\text { To- } \\
\text { mar } \\
\text { café }\end{array}$ & $\begin{array}{l}F() \\
\text { Fazer } \\
\text { exer- } \\
\text { cí- } \\
\text { cios }\end{array}$ \\
\hline $\begin{array}{l}\text { 6) Tem o hábito de } \\
\text { dormir durante o } \\
\text { dia em pequenos } \\
\text { intervalos? }\end{array}$ & $\begin{array}{l}A() \\
\text { Sim, as } \\
\text { vezes }\end{array}$ & $\begin{array}{l}\text { B ( ) } \\
\text { Sim, } \\
\text { todos } \\
\text { os dias }\end{array}$ & $\begin{array}{l}C() \\
\text { Não, } \\
\text { nunca }\end{array}$ & & & \\
\hline $\begin{array}{l}\text { 7) Quantas horas } \\
\text { em média, costu- } \\
\text { ma dormir diaria- } \\
\text { mente? }\end{array}$ & $\begin{array}{l}A() 3 \\
\text { horas } \\
\text { ou } \\
\text { menos }\end{array}$ & $\begin{array}{l}B() 4 \\
\text { horas }\end{array}$ & $\begin{array}{l}C() 5 \\
\text { horas }\end{array}$ & $\begin{array}{l}D(\text { () } 6 \\
\text { horas }\end{array}$ & $\begin{array}{l}\text { E () } 8 \\
\text { ho- } \\
\text { ras }\end{array}$ & $\begin{array}{l}F() \\
\text { Mais } \\
\text { de } 8 \\
\text { ho- } \\
\text { ras }\end{array}$ \\
\hline $\begin{array}{l}\text { 8) Conhece ou já } \\
\text { ouviu falar em Cro- } \\
\text { nobiologia? }\end{array}$ & () Sim & () Não & & & & \\
\hline
\end{tabular}

\section{RESULTADOS}

\section{Acadêmicos da 4a série Matutino}

A Tabela 1 demonstra os cronotipos dos acadêmicos do período matutino da $4^{\circ}$ série do Curso de Ciências Biológicas, 2006, da Universidade Paranaense na cidade de Cascavel-Pr. Dos 46 questionados do período matutino, $30,44 \%$ masculino e $69,56 \%$ feminino, com idades variando entre 19 e 36 anos, onde $32,60 \%$ apresentam idade entre 19-22 anos; $54,34 \%$ idade entre $23-26$ anos; $8,72 \%$ entre $27-30$ anos e apenas 4,34\% com mais de 31 anos.

Dos acadêmicos entrevistados no período matutino, com relação à questão de que horas gostariam de despertar pela manhã, nenhum gostaria de despertar entre $5 \mathrm{~h}$ e $6 \mathrm{~h}$,
Tabela 1. Freqüência dos cronotipos dos acadêmicos da $4^{\circ}$ série período matutino do Curso de Ciências Biológicas.

\begin{tabular}{|c|c|c|}
\hline Cronotipo & Frequência & $\%$ \\
\hline $\begin{array}{c}\text { Definitivamente } \\
\text { Matutino }\end{array}$ & 04 & $8,70 \%$ \\
\hline $\begin{array}{c}\text { Moderadamente } \\
\text { Matutino }\end{array}$ & 13 & $28,27 \%$ \\
\hline Intermediário & 02 & $43,48 \%$ \\
\hline $\begin{array}{c}\text { Definitivamente } \\
\text { Vespertino }\end{array}$ & 07 & $15,21 \%$ \\
\hline $\begin{array}{c}\text { Moderadamente } \\
\text { Vespertino }\end{array}$ & & \\
\hline
\end{tabular}

$13 \%$ gostaria de despertar entre $6 \mathrm{~h}$ e $7 \mathrm{~h}, 72 \%$ gostaria de despertar entre $7: 30 \mathrm{~h}$ e $10 \mathrm{~h}, 13 \%$ revelou que gostaria de despertar entre $10 \mathrm{~h}$ e $11 \mathrm{~h}$, e apenas $2 \%$ relatou que gostaria de despertar entre $11 \mathrm{~h}$ e $12 \mathrm{~h}$.

Em relação ao questionamento sobre o horário que gostariam de realizar atividades mentalmente desgastantes, $78 \%$ revelou que gostaria de realizar as atividades entre $8 \mathrm{~h}$ e $10 \mathrm{~h}, 2 \%$ entre $11 \mathrm{~h}$ e $13 \mathrm{~h}, 7 \%$ respondeu que seria entre $15 \mathrm{~h}$ e $17 \mathrm{~h}$ e $13 \%$ entre $19 \mathrm{~h}$ e $21 \mathrm{~h}$.

Quando questionados sobre o cansaço da primeira hora do dia, logo após levantar-se obtivemos: $4,35 \%$ sentem-se muito cansados, $43,48 \%$ sentem-se mais ou menos cansados, $34,78 \%$ sentem-se sem cansaço, porém não em plena forma e 17,39\% sentem-se em plena forma.

Com relação à predisposição natural para fazer caminhada entre $22 \mathrm{~h}$ e $23 \mathrm{~h}$ três vezes por semana dos acadêmicos questionados apenas 15,21\% responderam que estariam em ótima forma, $32,62 \%$ estariam em forma, $30,43 \%$ teriam dificuldades e ainda $21,74 \%$ acreditam que seria muito difícil.

Através das questões estruturadas podemos obter percentuais que nos permite identificar hábitos de sono dos acadêmicos entrevistados.

Dos 46 acadêmicos entrevistados no período matutino $50 \%$ responderam que costumam acordar durante o período de sono noturno, enquanto que os $50 \%$ restantes não costumam acordar durante este período, dos $50 \%$ dos entrevistados que costumam acordar durante o sono noturno, $30,43 \%$ responderam que acordam apenas 01 vez durante a noite, 43,48\% acordam 2 vezes durante o sono, $13,05 \%$ responderam que costumam acordar em média 3 vezes, 8,70\% acordam cerca de 4 vezes e 4,34\% possuem o hábito 
de despertar 5 vezes durante o sono noturno.

Os acadêmicos quando questionados sobre quando acordam durante o sono noturno e depois voltam a dormir se sentem cansados ao despertar pela manhã, 19,57\% dos entrevistados respondeu que se sentem nada cansados, 56,52\% sente-se um pouco cansados e $23,91 \%$ responderam que se sente muito cansado ao despertar.

Quando abordados sobre o uso de algum medicamento para dormir, $17,40 \%$ dos entrevistados responderam que utilizam medicamentos para dormir e $82,60 \%$ responderam que não faz uso de medicamentos.

Ao serem questionados sobre hábitos antes de dormir, $21,74 \%$ dos acadêmicos relatou possuir o hábito de comer, 58,69\% possuem o hábito de ver televisão, 6,53\% costumam ouvir música ou deixar o som ligado, 4,34\% costumam fumar antes de dormir, 6,53\% tomam café e 2,17\% possuem o hábito de realizar exercícios físicos.

$\mathrm{Na}$ questão para avaliar se os entrevistados possuem o habito de dormir durante o dia em pequenos intervalos, $69,57 \%$ responderam que às vezes dormem durante 0 período diurno, 4,34 relataram dormir todos os dias e $26,09 \%$ dizem não dormir durante o dia.

$\mathrm{Na}$ questão sobre quantas horas em média os entrevistados costumam dormir diariamente, $8,70 \%$ responderam que costumam dormir cerca de 3 horas ou menos por noite, $4,35 \%$ responderam que costumam dormir em média 4 horas, 8,70\% responderam que possuem o hábito de dormir 5 horas, $26,08 \%$ possuem o hábito de dormir 6 horas, $45,65 \%$ costumam dormir 8 horas e $6,52 \%$ possuem o hábito de dormir mais de 8 horas por noite.

Quando questionado se conhece ou já havia ouvido falar em cronobiologia, 54,34\% responderam que sim e $45,66 \%$ responderam que nunca haviam ouvido falar em cronobiologia.

\section{Acadêmicos da $4^{\mathrm{a}}$ série Noturno}

A Tabela 2 demonstra os cronotipos dos acadêmicos do período noturno da $4^{\circ}$ série do Curso de Ciências Biológicas, 2006, da Universidade Paranaense na cidade de Cascavel - Pr.

Dos 32 questionados do período noturno, $43,75 \%$ masculino e $56,25 \%$ feminino, com idades variando entre 19 e 41 anos, onde $27,38 \%$ apresentam idade entre $19-22$ anos; $32 \%$ idade entre 23-26 anos; $15,62 \%$ entre $27-30$ anos, $6,25 \%$ entre $31-34$ anos; $12,5 \% 35-38$ anose $6,25 \%$ com mais de 38 anos.

Dos acadêmicos entrevistados no período noturno, com relação à questão de que horas gostariam de despertar pela manhã, nenhum gostaria de despertar entre $5 \mathrm{~h}$ e $6 \mathrm{~h}, 9 \%$ gostaria de despertar entre $6 \mathrm{~h}$ e $7 \mathrm{~h}, 75 \%$ gostaria de despertar entre $7: 30 \mathrm{~h}$ e $10 \mathrm{~h}, 13 \%$ revelou que gostaria de despertar entre $10 \mathrm{~h}$ e $11 \mathrm{~h}$, e apenas $3 \%$ relatou que gostaria de despertar entre $11 \mathrm{~h}$ e $12 \mathrm{~h}$.

\begin{tabular}{|c|c|c|}
\hline Cronotipo & Frequência & $\%$ \\
\hline $\begin{array}{c}\text { Definitivamen- } \\
\text { te Matutino }\end{array}$ & 01 & $3,12 \%$ \\
\hline $\begin{array}{c}\text { Moderadamen- } \\
\text { te Matutino }\end{array}$ & 09 & $28,13 \%$ \\
\hline Intermediário & 01 & $30 \%$ \\
\hline $\begin{array}{c}\text { Definitivamente } \\
\text { Vespertino }\end{array}$ & 05 & $15,63 \%$ \\
\hline $\begin{array}{c}\text { Moderadamente } \\
\text { Vespertino }\end{array}$ & $05 \%$ \\
\hline
\end{tabular}

Tabela 2. Freqüência dos cronotipos dos acadêmicos da $4^{\circ}$ série período noturno do Curso de Ciências Biológicas.

Em relação ao questionamento sobre o horário que gostariam de realizar atividades mentalmente desgastantes, $66 \%$ revelou que gostaria de realizar as atividades entre $8 \mathrm{~h}$ e $10 \mathrm{~h}, 6 \%$ entre $11 \mathrm{~h}$ e $13 \mathrm{~h}, 19 \%$ respondeu que seria entre $15 \mathrm{~h}$ e $17 \mathrm{~h}$ e $9 \%$ entre $19 \mathrm{~h}$ e $21 \mathrm{~h}$.

Em relação ao cansaço que sente na primeira hora do dia, logo após levantar, verificou-se que: $18,75 \%$ sentem-se muito cansados, $21,88 \%$ sentem-se mais ou menos cansados, $50 \%$ sentem-se sem cansaço, porém não em plena forma e 9,37\% sentem-se em plena forma.

Com base na pré-disposição natural para fazer caminhada entre $22 \mathrm{~h}$ e $23 \mathrm{~h}$ três vezes por semana verificou-se que: $21,87 \%$ acreditam que estaria em ótima forma, $21,87 \%$ estaria em forma, $46,88 \%$ teria dificuldades e $9,38 \%$ seria muito difícil.

Dos 32 acadêmicos entrevistados no período noturno, $40,63 \%$ responderam que possuem o habito de acordar durante o sono noturno e $59,37 \%$ responderam que não costumam acordar durante o sono. Dos 40,63\% entrevistados que costumam acordar durante o sono noturno, 30,77\% responderam que costumam despertar 1 vez durante o sono, $38,47 \%$ costumam despertar 2 vezes, $15,38 \%$ possuem o habito de acordar 3 vezes, 7,69\% despertam 4 vezes e 7,69\% costumam despertar 5 vezes. 
Quando questionados se ao acordar durante o sono noturno sentem-se descansados ao despertar pela manhã $34,37 \%$ responderam que não se sentem nada cansados $53,13 \%$ responderam que se sentem um pouco cansados e 12,5\% responderam que se sentem muito cansados.

$\mathrm{Na}$ questão referente ao uso de algum tipo de medicamento para dormir, $100 \%$ dos entrevistados respondeu que não faz uso de medicamentos.

Ao serem questionados sobre hábitos antes de dormir, 28,13\% dos acadêmicos relatou possuir o hábito de comer, $37,5 \%$ possuem o hábito de ver televisão, 15,62\% costumam ouvir música ou deixar o som ligado, nenhum dos acadêmicos relatou fumar antes de dormir, 12,5\% tomam café e 6,25\% possuem o hábito de realizar exercícios físicos.

$\mathrm{Na}$ questão para avaliar se os entrevistados possuem 0 habito de dormir durante o dia em pequenos intervalos, $69,57 \%$ responderam que às vezes dormem durante 0 período diurno, 4,34 relataram dormir todos os dias e 26,09\% dizem não dormir durante o dia.

Com relação a quantas horas de sono diariamente, nenhum acadêmico diz dormir apenas 3 horas durante o dia, 6,25\% diz dormir 4 horas, 9,38\% relatou dormir 5 horas, $46,87 \%$ relatou dormir aproximadamente 6 horas diárias, $37,5 \%$ diz dormir por 8 horas e nenhum acadêmico relatou dormir mais de 8 horas diárias.

Dos acadêmicos do $4^{\circ}$ ano noturno $71,88 \%$ diz conhecer ou já ter ouvido falar em cronobiologia sendo que $28,12 \%$ disseram desconhecer o significado de cronobiologia.

\section{DISCUSSÃO}

Embora conhecida em vários países, somente a partir dos anos 80 a Cronobiologia tornou-se tema de estudos no Brasil. Desde então, essa nova área do conhecimento é objeto de pesquisa no meio acadêmico da área biológica. Pesquisadores da área da saúde pouco a pouco passaram a utilizar ferramentas cronobiológicas para compreender e interpretar eventos fisiológicos que variam regularmente ao longo do tempo. Contudo, a difusão desse conhecimento entre os profissionais da saúde e, conseqüentemente, sua aplicação na prática clínica têm sido praticamente incipientes no país.

Conforme os resultados obtidos nos remetem em ambas as turmas para uma maior predominância do cronotipo intermediário, sendo que este cronotipo apresenta uma maior adaptação possuindo um bom rendimento a qualquer horário em que venha realizar atividades. Os acadêmicos que possuem cronotipo definitivamente matutino e os moderadamente matutinos costumam ser mais ativos pela manhã, dormem e também acordam mais cedo ${ }^{4,7-9}$.

Os cronotipos definitivamente vespertinos e os moderadamente vespertinos são indivíduos que costumam acordar e dormir tarde, sendo que o nível de alerta e desempenho se encontra menos desenvolvido no período matutino estando mais desenvolvido durante a tarde e a noite ${ }^{4,7-9}$.

Através dos resultados obtidos podemos verificar que os acadêmicos do período matutino apresentam boa possibilidade de manter o estado de alerta para estudar neste horário, uma vez que apenas $19,55 \%$ possuem cronotipo em desacordo com o horário em que estudam, entre os acadêmicos do período noturno $31,25 \%$ encontram-se em horários de estudo incompatíveis com seu cronotipo. O fato de estudarem em horários contrários ao seu relógio biológico, pode se dar pela necessidade de trabalharem durante o dia, ou então pela falta de conhecimento de seu cronotipo podendo vir a prejudicar seu desenvolvimento acadêmico18.

A realização de atividades que estejam em desacordo com os ritmos biológicos, pode causar conseqüências diversas, desde distúrbios de humor, problemas de sono, estresse emocional, desordens gastrointestinais e hipertensão $0^{2-4,8,12-13,18,19-22}$.

Em relação aos despertares durante o período de sono noturno, $50 \%$ dos alunos do período matutino responderam que costumam acordar durante o período de sono noturno contra $40,63 \%$ dos entrevistados do período noturno.

Os distúrbios do sono incomodam e prejudicam o desempenho durante o dia seguinte. Algumas pessoas sofrem de distúrbios do sono quase toda noite, ficando cronicamente cansadas e improdutivas interferindo assim nos processos de aprendizagem e desempenho profissional18. Outras também são vítimas de ataques indesejáveis de sono durante $\mathrm{O} \mathrm{dia}^{4,5}$.

Dormir a noite parece fazer parte da ordem natural das coisas. A alteração desta ordem é percebida pelo corpo ou pela mente, que se comunicam com a pessoa, seja pedindo para dormir, seja, mais enfaticamente, cobrando o sono3.

Geralmente após sucessivos despertares, 
os indivíduos sentem-se cansados ao acordar, fator este que demonstra a importância da qualidade do sono e não da quantidade. No período matutino, $17,40 \%$ dos entrevistados revelaram que consomem medicamentos para dormir, enquanto que nenhum dos acadêmicos do período noturno relataram o uso de medicamentos 23 .

Pílulas para dormir realmente ajudam as pessoas a dormir, mas causam outros problemas. As pessoas podem dormir sob o efeito de uma dessas drogas, mas provavelmente se sentirão entorpecidas e cansadas no dia seguinte. Além disso, as pessoas desenvolvem tolerância a esses medicamentos, tornando-se dependentes e apresentando insônia e/ou rebote ao parar de tomá-los ${ }^{5}$.

O hábito de comer, ver televisão, ouvir música, entre outros hábitos antes de dormir, pode influir na qualidade do sono, pois influencia na audição, visão, impedindo o relaxamento. O hábito de comer e dormir com o estômago cheio, causa sua distensão e pesadelos ${ }^{23,24}$.

Quanto ao hábito de dormir durante o dia, este parece ser a solução para repor o sono do período noturno, mas durante o sono diurno a pessoa passa menos tempo na cama ocorrendo uma redução no sono REM durante o período noturno ${ }^{2}$.

Verificou-se que no período matutino $45,65 \%$ dos acadêmicos entrevistados possuem o hábito de dormir cerca de 8 horas diárias, talvez pelo fato de muitos não trabalharem e apesar de acordarem cedo, possuem a opção de deitar-se mais cedo. Os acadêmicos do período noturno $37,5 \%$ relataram dormirem em média 8 horas diárias. Isso pode ser justificado pelo fato destes acadêmicos trabalharem durante o dia e estudarem no período noturno, sendo que alguns não moram na cidade onde estudam necessitando de um período de viagem antes de poder deitar-se para dormir.

Muitas vezes os pais preocupados em oferecer o "melhor" para os filhos colocam-nos simultaneamente em várias atividades, proporcionandoIhes uma rotina diária muito desgastante e que exige um número de horas de vigília maior que o ideal, levando-os a privação de sono. Outras vezes, a opção é do próprio sujeito, que encurta seu período de sono para ficar na internet ou passeando com os amigos até altas horas. Outra questão que deve ser compreendida são a dos cronotipos. É sabido que na população existem três diferentes cronotipos: matutinos, intermediários e vespertinos. Estes, devido as suas características fisiológicas, possuem horários bastante distintos de dormir e acordar ${ }^{16,17}$.

É importante saber que os horários de dormir e acordar estão diretamente relacionados à produção de diferentes hormônios, como a melatonina, o cortisol e o hormônio do crescimento. Na adolescência, devido à verdadeira revolução hormonal que se instalam muitos sujeitos que são geneticamente matutinos e que nunca tiveram problemas para levantar cedo durante a infância tornam-se "vespertinos hormonais". Como já mencionado, aumentam também a sua necessidade de sono. Desta forma, entre a população de adolescentes vamos encontrar cerca de $50 \%$ de comportamento vespertino, enquanto na infância e na vida adulta os vespertinos representam menos de $10 \%$ da população ${ }^{25,26}$.

Dos acadêmicos do período matutino, $54,34 \%$ responderam que já haviam ouvido falar em cronobiologia contra $71,88 \%$ dos entrevistados do período noturno, esta desinformação sobre cronobiologia ocorre devido ao fato de ser um assunto novo pouco divulgado. Um novo ramo científico denominado de Cronobiologia diz que o organismo funciona segundo o compasso da natureza. Distúrbios de sono, saúde, o trabalho, desempenho escolar, tudo seria questão de $\operatorname{ciclos}^{4,8,13,19}$.

Num futuro não muito distante, a cronobiologia estará fundamentando discussões sobre a organização de programas de educação, orientando desde a programação de atividades até mesmo a definição mais precisa das etapas do aprendizado ${ }^{6}$.

O planejamento das atividades escolares deverá ser vista de um prisma cronobiológico. Isso significa organizar atividades de modo a contemplar momentos de maior ou menor rendimento nas tarefas escolares, seja do ponto de vista dos alunos ou dos professores. O custo orgânico e comportamental de uma tarefa escolar não é o mesmo nas diferentes horas do dia e modificações de programas levando em consideração esse fator tem sido testado com sucesso ${ }^{27,28}$.

Os educadores têm colocado que aprendizagem e desenvolvimento requerem percepção, atenção e memorização. Portanto, a cronobiologia enquanto ciência deve ser divulgada cada vez mais, principalmente entre futuros profissionais do campo de ensino, pois eles estarão à frente das decisões, dos planejamentos e terão a oportunidade de promover mudanças na organização do ambiente de trabalho e das escolas, objetivando com isso um melhor rendimento a todos. 


\section{CONCLUSÃO}

O conhecimento da cronobiologia é de suma importância para que todos os indivíduos possam vir a ter uma vida de maior qualidade, podendo se adaptar melhor aos horários compatíveis ao seu cronotipo e tendo um desempenho meIhor para a realização das mais diversas atividades.

Sugerimos que um diário relacionado aos hábitos de sono, sendo sendo preenchido por um determinado período de tempo, seja um instrumento e complemento dos dados relacionados aos habitos e horários de sono, pois os indivíduos identificariam e se conscientizariam melhor dessa rotina ao preenchê-lo diariamente, descobrindo aspectos que podem influenciar e complementar este estudo.

\section{REFERÊNCIAS}

1.Menna-Barreto L, Marques N. Cronobiologia: princípios e aplicações. São Paulo: Editora Universidade de São Paulo, 1997, 328p.

2.Gaspar S, Moreno C, Menna-barreto L. Os Plantões Médicos, o sono e a ritmicidade biológica. RAMB 1998;44:33-8.

3.Rotenberg L, Portela LF, Marcondes WB, Moreno C, Nascimento CP. Gênero e trabalho noturno: sono, cotidiano e vivências de quem troca a noite pelo dia. Cad Saúde Pub 2001;17:62-5.

4.Mello MT, Esteves AM, Comparoni A, Silva AAB, Tufik T. Avaliação do padrão e das queixas relativas do sono, cronotipo e adaptação ao fuso horário dos atletas brasileiros participantes das Paraolimpíadas em Sidney - 2000. Rev Bras Med Esporte 2002;8:122-8.

5.Kolb B, Whishaw J. Neurociência do Comportamento. São Paulo: Manole, 2002, 664p.

6.Cipolla-Neto J, Campa A. Ritmos biológicos. In: Aires MM. Fisiologia. Rio de Janeiro: Guanabara Koogan, 1991, p.17-9.

7.Zubioli MAS, Miranda-Neto MH, Santana DMG. Avaliação dos cronotipos dos auxiliares de enfermagem do hospital santa casa de Paranavaí - PR. Arq Cienc Saúde Unipar 1998;2:241-56.

8.Asinelle MEC, Miranda-Neto MH, Iwanko NS, Santana DMG. Identificação dos cronotipos de alunos do curso de enfermagem. Arq Cienc Saúde Unipar 1998;2:57-67.

9.Stabille SR, Gongora EM, Miranda-Neto MH. Cronotipo e horários adequados para o trabalho de servidores técnicoadministrativos do centro de ciências biológicas da Universidade Estadual de Maringá, no ano 2000. Arq Cienc Saúde Unipar 2001;5:227-33.

10.Burin I, Stabille SR. Identificação dos Cronotipos de Acadêmicos do Curso de Ciências Biológicas da Universidade Estadual de Maringá Durante o Ano Letivo de 2000. Arq Cienc Saúde Unipar 2002;6:17-24.

11.Almondes KM, Araújo JF. Padrões do Ciclo Sono-Vigília e suas Relações com a Ansiedade em Estudantes Universitários. Est Psicol (Natal) 2003;8:37-44.

12.Neves WS, Morioka RY, Koga AC, Aparecida F, Joveli Júnior J, Caldeira JC. Cronobiologia e suas Aplicações na Prática Médica. Rev HB Cient 2000;7:74-7.
O presente estudo aponta que os acadêmicos matriculados no período matutino, condizem com o seu cronotipo matutino e por uma possível adaptação a outros cronotipos, mostrando-se na maioria, ser intermediário. Para os acadêmicos do período noturno, o cronotipo intermediário mostrou-se presente, no entanto, houve uma grande freqüencia do cronotipo matutino, não condizendo com seus horários de estudo e hábitos de sono. Sugerimos que um diário relacionado aos hábitos Estudos comparativos sobre a relação cronotipo e médias aritméticas obtidos no âmbito escolar, poderão demonstrar o mecanismo de adaptação cronobiológico à aqueles horários. Portanto a cronobiologia deve ser levada para os mais diferentes ambientes, sejam eles de trabalho e escolares.

13.Fabichak CA, Douglas CR. Tratado de Fisiologia Aplicado a Nutrição. São Paulo: Editora Robe Copyright, 2002, 1046p.

14.Menna-barreto L, Marques N. O Tempo dentro da vida, além da vida dentro do tempo. Cienc Cult 2002;54:32-7.

15.Araújo EJA, Ferreira JR. Análise crítica dos cronotipos de acadêmicos do primeiro período do curso de biologia da universidade católica de Goiás. Arq Cienc Saúde Unipar 2001;5:95103.

16. Horne JA, Ostberg O. A self-assessment questionnaire to determine morningness-eveningness in human circadian rhytms. Int J Chronobiol 1976;4:97-110.

17.Cardinali DP, Golombeck DA, Rey RAB. Relojes y calendários biológicos: la sincronia Del hombre com el médio ambiente. Buenos Aires: Fondo de Cultura Econômica de Argentina, 1992, p.59-78.

18.Leconte P. Chronobiological rhythm constraints of memory processes. Arch Gerontol Geriatr 1989;1(Suppl):21-35.

19.Bortolotto LA. Implicações Clínicas dos Ritmos Biológicos do Sistema Cardiovascular. RBC 1999;1:158-62.

20.Luria AR. Fundamentos de Neuropsicologia. Rio de Janeiro: Livros Técnicos e Científicos SA, 1981, 346p.

21.Junker U, Wirz S. Chronobiology: influence of circadian rhythms on the therapy of severe pain. J Oncol Pharm Pract 2009;15:67-78.

22.Pandi-Perumal SR, Moscovitch A, Srinivasan V, Spence DW, Cardinali DP, Brown GM. Bidirectional communication between sleep and circadian rhythms and its implications for depression: lessons from agomelatine. Prog Neurobiol 2009;88:26471.

23.Reimão R. Durma bem. São Paulo: Atheneu, 1997, 106p.

24.Nielsen TA. Chronobiological features of dream production. Sleep Med Rev 2004;8:403-24.

25.Touitou Y. The aging of biological rhythms in man. Pathol Biol (Paris) 1987;35:1005-12.

26.Touitou Y, Bogdan A, Haus E, Touitou C. Chronobiological approach of aging. Pathol Biol (Paris) 1996;44:534-46.

27.Crépon P. Les rythmes de vie de l'enfant. Du tout petit á I'adolescent. Paris: Retz, 1983, 157p.

28.Testu F. Chronopsycologie et rythmes scolaires. 2 ed. Paris: Masson, 1991, $120 \mathrm{p}$. 